\title{
AS REPRESENTAÇÕES SOCIAIS DE \\ DIRETORES ESCOLARES DOS ANOS \\ INICIAIS DO ENSINO FUNDAMENTAL \\ SOBRE A FORMAÇÃO DE PROFESSORES
}

Luiz Carlos Carvalho de Oliveira

Luis Carlos Sales

\section{RESUMO}

A temática deste artigo trata da formação de professores. Seu objetivo é analisar as representações sociais de diretores escolares dos anos iniciais do Ensino Fundamental sobre formação de professores. Em específico, investigar as características que os diretores mais valorizam nos professores e identificar as políticas de formação de professores existentes nas escolas da rede pública municipal de Teresina. O interesse por essa temática surgiu a partir das evidências de uma pesquisa de doutorado, que, ao estudar a qualidade na educação, concluiu que a qualidade do ensino está fortemente relacionada ao "bom professor". O estudo em questão tomou como referência a Teoria das Representações Sociais de Serge Moscovici, tendo como participantes da pesquisa, pais, professores e alunos. As questões investigadas são as seguintes: na perspectiva do diretor escolar da escola pública dos anos iniciais é preciso ter formação para ser um bom professor dos anos iniciais do ensino fundamental? Será que para o diretor de escola pública municipal de Teresina, a formação é importante e faz diferença no desempenho das escolas? Quais são as representações dos diretores quanto a formação do professor? Quais as características que os diretores valorizam nos professores? Que programas de formação existem nas escolas da rede pública municipal? Esta pesquisa é relevante porque visa preencher uma lacuna no campo da formação de professores e dos estudos sobre a qualidade na educação, no sentido de contribuir com as políticas educacionais. Com isso, justifica-se a necessidade de apreender as representações sociais de diretor de escola acerca da formação de professor, com vistas a trazer luzes ao debate público sobre a qualidade da escola pública. A Teoria das Representações Sociais busca apreender o senso comum partilhado por um grupo sobre um determinado fenômeno social. Como instrumento de coleta de dados, foram utilizadas entrevistas semi-estruturadas, as quais foram realizadas, individualmente, com 30 diretores escolares. O material coletado foi submetido a uma análise de conteúdo. Os diretores afirmam que colaboram com o processo de Formação Continuada e a nomearam como Momento de Atualização. Representam a formação como um processo voltado para o domínio de sala de aula e para a aquisição de conteúdos. Valorizam mais o compromisso do professor que sua titulação, ou seja, valorizam pouco o fato de o professor possuir pós-graduação. Do ponto de vista da gestão escolar, ter um bom professor corresponde a ter um professor que cumpre o planejamento acordado para sua escola. E ainda, os sujeitos afirmam uma conexão entre a promoção de uma formação de professores através do processo de Formação Continuada e a qualidade na Educação, notadamente de uma educação pública de qualidade. Por fim, acredita-se que o estudo das representações sociais da formação de professores para

Professor Doutor da Universidade Estadual do Piaú (UESPI). Mestre em Educação (UFPI),

Professor Doutor Orientador do PPGed da Universidade Federal do Piauí (UFPI). 
diretores escolares contribui para se refletir sobre essa formação, sua influência na prática docente dos futuros professores dos anos iniciais do ensino fundamental.

Palavras-chave: Educação. Formação de Professores. Qualidade na Educação. Representações Sociais.

\begin{abstract}
The theme of this article deals with teacher training. Your goal is to analyze the social representations of school principals in the early years of elementary school on teacher training. In particular, investigate the features most valued directors in teachers and identify existing teacher training policies in schools of the municipal network Teresina. Interest in this theme arose from the Sales findings $(2009$, p.155) that by studying the quality of education, concluded that the quality of education is strongly related to the "good teacher." Sales of the studies taken as reference the Theory of Social Representations of Serge Moscovici, using as participants in the research, parents, teachers and students. The investigated issues are as follows: Against the background of the school director of public school in the early years we need to be trained to be a good teacher in the early years of elementary school? Does the director of the municipal public school in Teresina, training is important and makes a difference in the performance of schools? As the directors represent the training of teachers? What are the characteristics that directors value on teachers? What training programs exist in schools of public health system? This research is important because it aims to fill a gap in the field of teacher training and studies on the quality of education, to contribute to the educational policies. With this justifies the need to apprehend the social representations of school principal about the teacher training, in order to bring light to the public debate on the quality of public school. The Social Representation Theory attempts to grasp the common sense shared by a group of a particular social phenomenon. The collection of research data that originated this research took place through semi-structured interviews conducted individually with 30 school principals. Data analysis was performed from qualitative procedure. According to respondents, the formation of effective up teachers with continuing education. The directors suggested when talking about the Teacher Training, claim that contribute to the process of Continuing Education and named as Update Point. Besides the centrality occupied by the sense of continuing education as Update moment, the directors also represent as a process facing the Classroom and Domain for Content Acquisition, with a high percentage in the consensual universe of directors. The main feature of a good teacher is the commitment and the teacher must, in the teaching of the Early Years of elementary school, have warmth, Identity with the profession and ability to plan, specific challenges of teaching in Years Elementary School Initials. The main feature of the answers is that the directors value most teachers' commitment to their degree. That is, they just value the fact that the teacher has graduate. From the point of view of school management, have a good teacher is like having a teacher who meets the agreed planning for your school. And yet, the subjects assert a connection between the promotion of teacher training through the Continuing Education process and quality in education, especially a quality public education.
\end{abstract}

Keywords: Education. Teacher Training. Quality in Education. Social Representations. 


\section{INTRODUÇÃO}

O presente artigo busca compreender as representações sociais da formação de professores. O estudo visa analisar as representações sociais de diretores escolares dos Anos Iniciais do Ensino Fundamental sobre a formação de professores. E como objetivos específicos: identificar as políticas de formação de professores no Brasil e analisar os programas de formação de professores existentes nas escolas da rede pública municipal de Teresina.

O interesse por essa temática surgiu a partir das evidências de pesquisa de Sales (2009, p.155) que, ao estudar a qualidade na educação, concluiu que a qualidade do ensino está fortemente relacionada ao "bom professor". Os estudos de Sales tomaram como referência a Teoria das Representações Sociais de Serge Moscovici. Participaram como sujeitos do referido autor, pais, professores e alunos.

A associação que se faz entre bom professor e qualidade do ensino talvez explique o grande investimento que se faz para melhorar a formação de professores, a qual, como objeto de estudo, está presente, como linha de pesquisa, na maioria dos Programas de Pós-Graduação em Educação brasileiros, além de ser o principal tema de trabalhos apresentados em congressos e encontros de pesquisas no país, ou seja, existe certo consenso que é a partir da formação que se pode ter bons professores e consequentemente, qualidade no ensino.

Considerando que as representações sociais variam conforme os sujeitos e os lugares de onde falam, e que os estudos de Sales (2009) não tiveram acesso às representações sociais dos diretores de escolas, sujeitos importantes na mediação entre professores e alunos, é que propomos a realização desta pesquisa, tendo o diretor de escola como sujeito desta investigação.

Esta pesquisa procura responder tais questões, bem como aprofundar os registros de campo de Sales (2009), estudando os significados que emergem da fala dos diretores/gestores quando se referem à formação de professores das escolas públicas municipais.

Na perspectiva do diretor da escola pública é preciso ter formação, para ser um bom professor dos anos iniciais do ensino fundamental? Daí o propósito de investigar as representações sociais de diretores como forma de aprofundar a temática da formação e especificamente, suas representações sobre a formação de professores. Será que para o diretor da escola pública municipal de Teresina, a formação é importante e faz diferença no desempenho das escolas? Como os diretores representam 
a formação do professor? Quais as características que os diretores valorizam nos professores? Que programas de formação existem nas escolas da rede pública municipal?

Portanto, de modo geral o artigo pretende analisar as representações sociais de diretores escolares dos anos iniciais do ensino fundamental sobre a formação de professores. E como desdobramento, evidencia as características que os diretores mais valorizam nos professores, bem como discute os programas de formação de professores existentes nas escolas da rede pública municipal de Teresina.

As perguntas fazem parte de um questionário de entrevista semi-estruturada aplicado a diretores escolas de escolas públicas municipais. A amostra foi delimitada a 30 diretores (as) de escolas públicas. A amostra é suficiente para dar conta das representações sociais envolvendo as mudanças nas funções do gestor educacional nas últimas décadas.

Esta pesquisa é relevante porque visa preencher uma lacuna no campo da formação de professores e dos estudos sobre a qualidade na educação, para dar subsídio às políticas educacionais de escolas públicas na cidade de Teresina - PI. Com isso, justifica-se a necessidade de entender melhor a figura do diretor enquanto gestor da escola pública, com o interesse específico de contribuir no debate público de construção de uma escola pública de qualidade. Discute-se a seguir, alguns aspectos considerados centrais na discussão sobre a formação de professores.

\section{ASPECTOS CENTRAIS DA DISCUSSÃO SOBRE A FORMAÇÃO DE PROFESSORES E A FORMAÇÃO CONTINUADA}

Nesse tópico serão descritos alguns dos aspectos considerados centrais na formação de professores, com vistas a fundamentar as discussões a serem desenvolvidas ao longo do artigo. Neste sentido, a formação de professores sempre esteve ligada à formação no sentido de se atualizar, reciclar, capacitar ou de manter uma educação contínua que permitisse passar para os professores aqueles conhecimentos e competências necessários ao aperfeiçoamento do processo de ensino.

A formação de professores, nesse sentido, passa a ser encarada como um expediente na busca de novos conhecimentos teórico-metodológicos para o desenvolvimento profissional em tempos de mudança.

E é no cenário dos Anos Iniciais do Ensino Fundamental que reflete-se a importância da formação como um dos fatores de desenvolvimento da qualidade na 
educação pública municipal e nos próprios docentes como aqueles profissionais que podem contribuir para a formação das novas gerações.

Imbernón (2010, p. 110), colaborando com essa perspectiva acrescenta que as mudanças de atitudes são fundamentais para motivar e reconhecer as emoções dos seus colegas e para o desenvolvimento de sua autoestima.

\begin{abstract}
A formação dos professores junto ao desenvolvimento de atitudes será fundamental. A formação deve ajudá-los a estabelecer vínculos afetivos entre si, a coordenar suas emoções, a se motivar e a reconhecer as emoções de seus colegas de trabalho, já que isso os ajudará a conhecer suas próprias emoções, permitindo que se situem na perspectiva do outro, sentindo o que o outro sente. Enfim, ajudá-los a desenvolver uma escuta ativa mediante a empatia e o reconhecimento dos sentimentos do outro. A formação dos professores deve favorecer, sobretudo, o desenvolvimento da autoestima docente, individual e coletiva.
\end{abstract}

Compreende-se, a partir dessa característica conceitual, outra característica que confere uma centralidade à formação de professores e refere-se às possibilidades de continuidade das trocas, dos debates sobre o cotidiano escolar, possibilitando ao professor reflexões sobre sua prática em sala de aula.

Para definir o processo de formação de professores oferecido nas escolas públicas municipais dos anos iniciais do Ensino Fundamental, optamos por defini-lo como formação continuada, que neste momento, expressa a amplitude necessária do conceito para ser desenvolvido ao longo deste artigo.

O significado da formação continuada não pode ser apenas o de colocar o professor a par das últimas pesquisas, como se isso bastasse para automaticamente modificar o seu fazer pedagógico.

Com a pesquisa bibliográfica foi possível observar que a concepção de formação continuada de professores predominante, é aquela que se apresenta como algo que pode contribuir para a qualidade do ensino e para o desenvolvimento profissional e pessoal dos professores.

A efetivação deste processo contínuo é que levará ao bom desempenho dos profissionais que atuam na educação pública brasileira, independente das funções que desempenhem: supervisores, diretores, coordenadores pedagógicos e professores. É imprescindível que esta formação continuada aconteça articulada com as outras duas etapas, efetivando-se na intersecção entre a formação inicial, a formação continuada e a prática profissional.

\title{
3 AS REPRESENTAÇÕES SOCIAIS DO DIRETOR ESCOLAR
}


De forma geral, a gestão da escola pública é um fenômeno social sobre a qual a maioria das pessoas, especialmente, aquelas que têm relação com o sistema educacional, construiu determinada representação. A representação social que os diretores têm sobre a formação de professores tem, além disso, enorme influência sobre como deve ser a gestão na hora de elaborar estratégias de mudança. Por essa razão, será realizada esta pesquisa, para conhecer o que circula na mente dos diretores sobre a formação de professores.

A Teoria das Representações Sociais busca apreender o senso comum de um determinado fenômeno social, compreender como um grupo de indivíduos, no caso os diretores enquanto gestores escolares, constrói um conjunto de saberes que orienta suas condutas. Ela é empregada para identificar, analisar e compreender as razões de um determinado fenômeno relacionado à Educação, e tem como foco o saber que os diretores de escola pública possuem sobre a formação de professores.

Em que sentido se fala de uma representação social? Em primeiro lugar, é partilhada por um grupo de indivíduos. Em segundo lugar é produzida coletivamente, é produto das interações e das comunicações no interior dos grupos, refletindo a situação de um grupo, os seus projetos e problemas. E no centro das representações, sua funcionalidade, ou seja, elas são teorias sociais práticas ou como refere Jodelet (2005), são um saber prático.

A Teoria das Representações Sociais é, em termos de história das ciências, muito recente. Em "A Psicanálise, sua imagem e seu público", Moscovici (1978) introduz a sua abordagem inédita das representações sociais, tomando como objeto de pesquisa a apropriação da psicanálise pelo grande público francês, transformando-a numa forma de conhecimento socialmente elaborado e partilhado enquanto saber prático do senso comum. Ele estabelece, nesse estudo, a apreensão de um social em movimento, transformado com a divisão do trabalho das sociedades modernas.

\section{A DISCUSSÃO DA FORMAÇÃO CONTINUAdA NO CONTEXTO DAS REFORMAS EDUCACIONAIS}

As políticas de formação continuada implementadas no Brasil, a partir de 1990, inscreveram-se num contexto em que a escola pública foi bastante questionada quanto à sua qualidade, haja vista os baixos resultados escolares obtidos por meio de testes padronizados e de testes internacionais. 
Dessa forma, fica claro que, embora tenha ocorrido a ampliação do acesso à escola pública, não estão garantidas as condições necessárias para uma educação de qualidade que garanta a permanência e o sucesso escolar dos alunos.

Novamente, Imbernón (2010, p.7-8) reconhece que há muita coisa que funciona ou que avançou bastante, no conhecimento teórico e na prática da formação continuada, mas deixa evidente que desde o início do séc. XXI deu-se um retrocesso, pois muitas das teorias e práticas anteriores mantiveram-se, embora reconheça que houve avanços e que reconheça que os contextos sociais que envolvem a formação continuada mudaram muito.

A partir dos anos 1980, o tema da formação assume relevância. Torna-se pauta em vários congressos, seminários relacionados à área educacional. O tema passa a ocupar espaço nas políticas públicas de educação. O que surge de novo?

De acordo com Feldmann (2009, p. 74), surge um novo cenário no mundo, com os novos padrões de reestruturação econômica do capitalismo, uma reconfiguração do Estado, transformações na gestão escolar dos sistemas escolares, na escola e tudo isso acarretou mudanças no processo de formação de professores.

\subsection{Um novo perfil de gestão escolar na construção de uma escola pública de qualidade}

Nas duas últimas décadas, os termos administração e gestão têm sido utilizados na literatura de modo indistinto, como sinônimos, ou de modo a sugerir significados distintos entre eles. Os autores pretendem dar ao termo gestão uma dimensão mais ampla do que a dada à administração. Dessa forma, o termo administração remete a uma prática mais conservadora, enquanto a gestão implica uma perspectiva mais democrática.

Para essa temática, a gestão é aceita como uma evolução da administração. Portanto, não se ocupa do esforço despendido por pessoas isoladamente, mas com o esforço humano coletivo e com a utilização racional desse empenho.

Uma questão central no debate sobre a gestão da educação pública tem sido superar formas mais centralizadoras, clientelísticas, em direção a processos mais democráticos, o que inclui o aumento de mecanismos de participação dos cidadãos nos processos de tomada de decisão, gestão de ensino e gestão da política educacional. 


\subsection{O debate em torno da qualidade na educação pública}

A temática da qualidade aflora no debate sobre as reformas educacionais do Ensino Fundamental, junto à reformulação dos sistemas educacionais, onde as reformas começam com o diagnóstico do fraco rendimento.

Em decorrência disso, tornou-se preponderante o desenvolvimento de iniciativas que pudessem interferir diretamente nos quadros de baixa qualidade educacional, dimensionada por fracos resultados escolares, aferidos pelos sistemas nacionais de avaliação.

Esse diagnóstico que alcança a gestão das escolas acontece no contexto de reforma do Estado brasileiro que tiveram curso nos anos de 1990, onde foram implantados sistemas de avaliação estandardizados, percebendo a qualidade como um resultado a ser perseguido, introduzindo nas escolas públicas princípios de competitividade nos moldes das empresas e do mercado.

O discurso sobre a qualidade no universo das empresas tem sido transposto para a gestão da educação. Os aspectos obscuros nessa transposição são numerosos, começando pela indispensável distinção entre os significados dos projetos empresariais e educacionais, tarefa que pressupõe o reconhecimento tácito da maior complexidade dos projetos educacionais, em razão, sobretudo, da abrangência e da amplitude dos valores envolvidos.

Com efeito, de um lado, o pré-requisito para se discutir qualidade da educação é que esta seja para todos (quantidade) e, de outro, a qualidade é pré-requisito para se discutir a quantidade. $\mathrm{Na}$ perspectiva da expansão do acesso à escola, exige-se a construção de outra qualidade educacional, tendo em vista superar a tradição de um ensino público feito para uma minoria.

\section{METODOLOGIA}

A coleta de dados da pesquisa que originou este artigo deu-se por meio de entrevistas semiestruturadas realizadas, individualmente, com os 30 sujeitos da amostra. A análise de dados foi realizada a partir de dois procedimentos: um quantitativo e um qualitativo. O método quantitativo foi utilizado para computar a frequência de respostas a cada uma das perguntas constantes do roteiro de entrevista e apresenta-las em forma de tabelas. O método qualitativo teve por objetivo obter-se uma análise detalhada das respostas discursivas dos 30 sujeitos da pesquisa. A 
interpretação das respostas utilizou-se dos ensinamentos de Bardin (1977). Por meio da técnica análise categorial. O procedimento consistiu em analisar o conteúdo discursivo das justificativas dos entrevistados em cada resposta.

\subsection{Apresentação e discussão dos resultados}

O objetivo deste tópico é analisar os dados de entrevistas realizadas com 30 diretores escolares dos anos iniciais do ensino fundamental da Rede Pública Municipal de Ensino de Teresina. O material coletado possibilitou uma análise das comunicações das falas dos diretores que colaboraram com esta pesquisa.

A partir das respostas dadas pelos diretores às perguntas contidas no Roteiro de Entrevista, totalizando 4 questões, procedeu-se diversas leituras ao corpus das entrevistas até que aflorassem as categorias analíticas, em cada questão respondida pelos diretores. A seguir, é apresentada a análise realizada.

A interpretação dos dados, neste item, é apresentada com o apoio do referencial teórico proposto e/ou teorizações consultadas durante todo o processo de pesquisa. A questão 1 do roteiro de entrevista [Como você vê a Formação Continuada?] teve como objetivo identificar a importância que os diretores escolares dão a formação continuada de professores. A seguir, a Tabela 1 apresenta as categorias de respostas e seus respectivos percentuais.

Tabela 1 - Como você vê a formação continuada?

\begin{tabular}{lr}
\hline Categorias & $\mathbf{\%}$ \\
\hline Momento de Atualização & 60,0 \\
Domínio de Sala de Aula & 10,0 \\
Aquisição de Conteúdos & 10,0 \\
Troca de Experiências & 5,0 \\
Voltada para a Inclusão & 5,0 \\
Impacto na Aprendizagem & 5,0 \\
Espaço de Planejamento & 5,0
\end{tabular}

Fonte: Pesquisa de Campo, dez/2014.

Dentre as sete categorias que emergiram das falas dos diretores escolares, podese perceber que a categoria que apresentou o maior percentual foi Momento de Atualização $(60,0 \%)$, revelando que a formação continuada, para os diretores, tem a função de atualizar os professores frente às mudanças no trabalho docente e de um 
mundo em mudanças na forma de criar e produzir. As seguintes falas nos remetem a essa interpretação:

Eu acho imprescindível, principalmente, porque o professor tem que estar continuamente se aperfeiçoando, cursos para o professor frequentar. Deve estar sempre se atualizando em atualidades, com livros relacionados à sua prática, senão ele para de crescer (Diretor 2).

Eu acho a formação continuada necessária, infelizmente nem todos os docentes têm essa visão, mas é claro que é necessário estar constantemente se atualizando, buscando novos meios, novas metodologias, tentando acompanhar a evolução do mundo; que os professores se conscientizem da necessidade da formação continuada (Diretor 6).

É o que Imbernón (2010) denomina de tradição na formação continuada, ou seja, consiste na atualização dos professores com vista à ação prática. Muitos diretores comungam desta mesma representação sobre o processo de formação.

Neste sentido, a formação continuada contribui para o exercício da docência de seus professores, proporcionando a eles momentos específicos de estudo do referencial teórico da própria escola e assuntos que possam surgir no decorrer do processo formativo, ligados ao domínio de sala de aula e aquisição de conteúdos.

De acordo com Imbernón (2000, p.16), “[...] a aquisição de conhecimentos por parte do professor está muito ligada à prática profissional e condicionada pela organização da instituição educacional em que esta é exercida". Então, é legítima a concepção, segundo os gestores, de que a formação proposta pela escola, forma seu profissional para atender principalmente as especificidades do contexto da escola.

Na questão 1, ainda merecem destaque as categorias Domínio de Sala de Aula e Aquisição de Conteúdos, ambas com 10,0\%.

A questão 2 [Que saberes ou competências são necessárias para a Formação Continuada de Professores?] teve como objetivo saber que saberes, competências ou conteúdos são imprescindíveis na Formação Continuada e as possíveis razões para suas justificativas.

Tabela 2 - Que saberes ou competências são necessárias para a Formação Continuada de Professores?

\begin{tabular}{lr}
\hline Categorias & $\mathbf{\%}$ \\
\hline Abertura para a Inclusão do Aluno & 30,0 \\
Uso de Práticas Afetuosas & 25,0 \\
Domínio de Sala de Aula & 15,0 \\
Lidar com o Aluno Carente & 15,0
\end{tabular}


Fonte: Pesquisa de campo, dez./2014

Analisando a Tabela 2 verifica-se que as categorias Abertura para a Inclusão do Aluno (30\%) e Uso de Práticas Afetuosas (25\%), apresentam as maiores frequências, e são consideradas as principais a serem trabalhadas na Formação Continuada de Professores.

Portanto, a categoria Abertura para a Inclusão do Aluno (30\%) realça a importância do paradigma da Inclusão nos anos iniciais do ensino fundamental e constitui-se o principal saber que os diretores interlocutores declaram ser fundamental na Formação Continuada. As falas seguintes ilustram a referida categoria de resposta:

A graduação é algo muito incompleto mesmo, forma muito pouco e a formação continuada faz essa continuação. Agora precisaria trabalhar mais essa questão da afetividade na relação de ensino e aprendizagem, pois, às vezes, há professores que chegam até a chorar por não consegui realizar a aprendizagem. A culpa termina sendo toda do professor... Trabalhar também para ter preparo para receber os alunos no processo de inclusão, ter competência para receber alunos com outras dificuldades e transtornos. Ter conhecimentos da psicopedagogia (Diretor 16).

Os grandes problemas hoje estão ainda no que ainda não se investiu de forma efetiva, como: saber lidar com os alunos especiais, a tal da inclusão, os conhecimentos da psicologia, voltados para entender a aprendizagem, controle da disciplina, é isso o necessário! (Diretor 19).

As falas podem ser consideradas representativas dos sentidos que a inclusão escolar assume no cotidiano educacional, também ao levar-se em conta a necessidade de compreender e acompanhar os momentos de transição que os professores vivem na incorporação da inclusão de alunos com necessidades educacionais especiais pelo ensino comum.

No contexto da educação inclusiva, Mantoan (2003) afirma que:

Se, de um lado, é preciso continuar investindo maciçamente na direção da formação de profissionais qualificados, de outro, não se pode descuidar da realização dessa formação e deve-se estar atento ao modo pelo qual os professores aprendem, para se profissionalizar e para aperfeiçoar seus conhecimentos pedagógicos, e também a como reagem às novidades, aos novos possíveis educacionais (MANTOAN, 2003, p.81).

Em relação à questão 2, mais uma vez emergiu a Domínio de Sala de Aula, com $15,0 \%$. 
A questão 3 [Você apoia a Formação Continuada de Professores?] teve como objetivo aprofundar as ideias partilhadas pelos entrevistados acerca de suas representações em relação à Formação Continuada. Conforme as entrevistas, 90\% dos sujeitos confirmam que apoiam a formação continuada de seus professores e só $10 \%$ não apoiam, sendo que muitas vezes não apoiam pela forma como é conduzida essa formação.

Tabela 3 - Você apoia a formação continuada de professores?

\begin{tabular}{lll}
\hline SIM & NÃO \\
\hline & $90 \%$ & $10 \%$ \\
\hline
\end{tabular}

Fonte: Pesquisa de campo, dez./2014

A Tabela 4, a seguir, apresenta as categorias de respostas referentes às falas dos $90 \%$ que apoiam a Formação continuada, ao responderem SIM, conforme a Tabela 3.

Tabela 4 - Os $90 \%$ de diretores que apoiam a formação continuada relacionam esse tipo de formação com:

\begin{tabular}{lr}
\hline Categorias & $\mathbf{\%}$ \\
\hline Momento de Atualização & 45,0 \\
Formação como Capacitação & 30,0 \\
Uso de Práticas Afetuosas & 20,0 \\
Busca de parcerias com outras instituições & 5,0
\end{tabular}

Fonte: Pesquisa de campo, dez./2014

A categoria com maior frequência para justificar o apoio por parte dos diretores à Formação Continuada é a categoria Momento de Atualização, com 45\%. Esta categoria, também emergiu na questão 1 , e denota a intencionalidade na qual se direciona o foco do diretor escolar no sentido de alinhamento à racionalidade dos projetos educacionais conduzidos na escola pública municipal. Os trechos de entrevistas, a seguir, ilustram essa intencionalidade e a lógica do apoio:

Acho necessário, a direção colabora com a formação continuada, são liberados para fazer a formação. Essa é a oportunidade que o professor tem para realizar projetos; a formação continuada é um suporte para se atualizar e ver um material que já vem pronto para ajudar o professor, para dar resultado. É uma necessidade para trabalhar junto com a direção pedagógica de projetos e os meninos serão avaliados dentro dessa metodologia com meus alunos (Diretor 5). 
Mais é claro, no fundo, é na formação continuada que a gente se torna professor, no sentido de uma prática mais firme diante das dificuldades e de uma atualização constante em um mundo que exige uma atualização constante do professor! (Diretor 10).

Fica evidente o grande apoio manifesto na fala dos diretores quanto ao apoio à Formação Continuada, com o propósito de ser um momento de promover sua atualização. O que o diretor compreende como atualização? Pode-se inferir que a categoria se atrela ao fato de que os professores estão inseridos num mundo globalizado, onde a informação e a atualização é muito necessária para a sala de aula.

Neste sentido, Nóvoa (2002, p.23) deixa claro que "comunicar com a sociedade é também responder perante a sociedade", essa "atualização seria então uma forma do professor alcançar prestígio dentro da sociedade, ou ao menos, na comunidade onde está inserido pois, segundo o mesmo autor, a força de uma profissão, e nesse caso o professor, está definida, pela capacidade que ele tem em se comunicar com o seu público.

Uma segunda categoria com maior frequência para justificar o apoio por parte dos diretores à Formação Continuada é a categoria Formação como Capacitação $(30 \%)$. Esta categoria está relacionada com a anterior ou deriva dela, ou seja, deriva da categoria Momento de Atualização. Esta segunda categoria seria integradora da primeira categoria.

É, notadamente, mais um aspecto que revela o apoio de diretores escolares aos projetos de efetivação de uma Formação Continuada para os professores dos anos iniciais do ensino fundamental. Os diretores evidenciam as suas justificativas para esta questão, como podemos ver nas seguintes falas:

Eu acho que na universidade você sai graduado, mas não sai professor, quando você começa a fazer parte da Formação Continuada, aí é que você se torna um professor propriamente dito, com conteúdo e estratégia (Diretor 1).

Sim, da minha parte a função da direção é colaborar para que o professor tenha uma prática cada vez mais preparada, para dar conta das exigências avaliativas que estão na moda na educação. Formação continuada deve visar a preparação do conteúdo e do controle de sala de aula (Diretor 3).

O Uso de práticas afetuosas é a terceira categoria com maior frequência, para justificar o apoio por parte dos diretores à Formação Continuada, com 20\%. Essa categoria também emergiu na questão 3. Portanto, a afetividade deve perpassar todo o processo de ensino-aprendizagem, sendo mencionada reiteradamente pelos entrevistados no sentido de uma atitude de afetuosidade, como podemos notar a seguir: 
Com certeza, se a gente pudesse a todo mês, ter aquele dia só para a formação: falar de valores, falar da relação com a família. Estar preparado para vivenciar experiências de afetividade no ensino presenciado dia a dia com os alunos (Diretor 26).

Com certeza, nessa escola, sabemos da importância da formação continuada na formação para agir com afetividade no ensino do professor e que essa formação contribui para o desempenho de nossos alunos (Diretor 29).

A Questão 4 [O que precisa ter um “bom professor”?] teve como objetivo saber como os diretores de escola pública representam as características de um "bom professor".

As categorias, obtidas nas falas dos diretores, são recorrentes novamente, em relação às respostas já apresentadas, nas questões anteriores, conforme a Tabela 5, a seguir, a qual mostra as categorias que apontam as características de um "bom professor".

Tabela 5-O que precisa ter um "bom professor"?

\section{Categorias}

\section{Compromisso}

$50 \%$

Ter Afetuosidade

Identidade com a Profissão

Fonte: Pesquisa de campo, dez/2014.

Analisando as falas dos diretores, verifica-se que, em sua maioria, 50\% disseram que o bom professor tem como característica principal o Compromisso (visto como um professor comprometido com a escola). Em seguida, os sujeitos apontaram Ter Afetuosidade (com 30\%), Ter Identidade com a Profissão (com 15\%) e Habilidade para Planejar com um percentual de 5\%.

A característica principal das falas da maioria dos diretores entrevistados está expressa no valor que atribuem ao professor que tem compromisso. Para eles, vale mais um professor compromissado do que um professor pós-graduado na equipe da escola. Do ponto de vista da gestão, ter um bom professor corresponde a ter um professor que cumpre o planejamento acordado para sua escola.

Assim, é vital para o gestor, na construção do processo de qualidade na educação, procurar proporcionar a melhoria dos indicadores de sucesso de sua escola. As falas, a seguir, ilustram as características que deve ter um bom professor, segundo os diretores entrevistados: 
São várias qualidades: o comprometimento com a responsabilidade com o que tem que fazer, fazendo com insistência e persistência, ter esse compromisso de ensinar, o resto tudo vem junto! Aí assim, sem esse compromisso, não vai dar certo! (Diretor 5)

Deve ter conhecimento, domínio de sala de aula, no sentido de controle de sala de aula, saber lidar com o aluno das series iniciais. Enquanto gestor, eu valorizo o comprometimento e o dinamismo do professor na escola, que os resultados da turma são bons, esse é a característica de um professor que está se atualizando e trazer aulas sobre uma nova realidade (Diretor 6).

\section{CONCLUSÃO}

Analisando os resultados das respostas expressas pelos participantes desta pesquisa, percebe-se que o diretor escolar, de forma geral, apoia a formação de professores e a nomeia como formação continuada. Isto está bem caracterizado na questão 4 e a relacionam firmemente a um Momento de Atualização.

Ficou evidente, por meio das Representações Sociais apreendidas, que a formação continuada é valorizada pelos diretores escolares. Após a análise dos resultados, pode-se concluir que, para os diretores escolares, a característica principal do bom professor é o Compromisso e que o professor deve, na docência dos Anos Iniciais do Ensino Fundamental, ter Afetividade, Identidade com a Profissão e Habilidade para Planejar.

A característica principal observada é a de que os diretores valorizam mais o Compromisso do professor que a titulação de seus professores. Portanto, do ponto de vista da gestão escolar, ter um bom professor corresponde a ter um professor que cumpre o planejamento acordado para sua escola.

Por fim, os diretores fazem uma nítida conexão entre a promoção de uma formação de professores através do processo de Formação Continuada e a qualidade na educação, qualidade tão necessária para a maioria das escolas públicas brasileiras.

\section{REFERÊNCIAS}

ASSOCIAÇÃO NACIONAL DE POLÍTICA E ADMINISTRAÇÃO DA EDUCAÇÃ̃O. Programa de pesquisa política e gestão de educação no Brasil. Diretrizes metodológicas, Brasília, mar/jun, 1997.

ABRUCIO, Luiz Fernando. Gestão escolar e qualidade da educação: um estudo sobre dez escolas paulistas. Estudos \& Pesquisas Educacionais, São Paulo, n. 1, maio 2010.

AGUIAR, Márcia Ângela da S. A formação dos profissionais da educação no contexto atual e o PNE 2011-2020: avaliação e perspectivas. In: DOURADO, Luiz Fernandes. 
Plano Nacional de Educação (2011-2020): avaliação e perspectivas. Goiânia: Editora UFG; Belo Horizonte: Autêntica, 2011.

ALARCÃO, Isabel. (Org.). Formação reflexiva de professores: estratégias de supervisão. Porto: Porto Editora, 1998.

ALMEIDA, Maria Isabel de. Formação Contínua de professores em face das múltiplas possibilidades e dos inúmeros parceiros existentes hoje. In: ALMEIDA, Maria Isabel de. (Org.). Formação contínua de professores. Brasília: Ministério da Educação. Boletim 13, p.11-17. ago.2005

BALL, Stephen. Reformar escolas/reformar professores e os terrores da performatividade. Revista Portuguesa de Educação, v.15, n.2, 2002.

BARBOSA, Raquel Lazzari Leite (Org.). Formação de educadores: desafios e perspectivas. São Paulo: Unesp, 2003.

BARDIN, Laurence. Análise de conteúdo. Lisboa: Edições 70, 1977.

BEISIEGEL, Celso de Rui A qualidade do ensino na escola pública. Brasília: Líber Livro Editora, 2005.

BEHRENS, Marilda Aparecida. O paradigma da complexidade na formação e no desenvolvimento profissional de professores universitários. Educação, Porto Alegre, v.63, n.3, p. 439-455, set./dez. 2007.

BEHRENS, Marilda Aparecida; PEREIRA, Liandra. Os paradigmas e os reflexos da formação de professores na docência universitária. In: BEHRENS, Marilda Teresa; ENS, Romilda Teodora. Ser professor: formação e os desafios na docência. Curitiba: Champagnat, 2011.

BOGDAN, Robert; BIKLEN, Sari Knopp. Investigação qualitativa em educação: uma introdução à teoria e aos métodos. Porto: Porto Editora, 1994. 336 p. (Colecção ciências da educação ; 12)

BONAMIGO, Alicia; LIMA, Naira da Costa M. Aspectos da gestão escolar e seus efeitos no desempenho dos alunos nos anos iniciais do ensino fundamental. In: MARTINS, Angela Maria et al. Políticas e gestão da educação: desafios em tempos de mudança. Campinas: Autores Associados, 2013.

CABRAL NETO, Antonio; CASTRO, Alda Maria Duarte Araújo. Gestão escolar em instituições de Ensino Médio: entre a gestão democrática e gerencial. Revista

Educação \& Sociedade, Campinas, v. 32, n. 116, p. 745-770, jul./set. 2011.

Disponível em: <http://www.cedes.unicamp.br>Acesso em: 12 jul. 2015.

CAMARGO, R.; ADRIÃO, Theresa. Princípios e processos da gestão democrática do ensino: implicações para os conselhos escolares. Revista Chão de Escola, Curitiba, n. 2. 2000.

CANDAU, Vera Maria. Universidade e formação de professores: que rumos tomar? In: CANDAU, Vera Maria. (Org.) Magistério, construção cotidiana. Petrópolis: Vozes, 1997.

CASASSUS, Juan. A escola e a desigualdade. Brasília: Líber Livro Editora, Unesco, 2007. 
CASTRO, Maria Helena Guimarães; TIEZZI, Sérgio. A reforma do ensino médio e a implantação do Enem no Brasil. In: SCHWARTZMAN, Simon; BROCK, Colin. Os desafios da educação no Brasil. Rio de Janeiro: Nova Fronteira, 2005.

CASTRO, Alda Maria Duarte Araújo. Administração gerencial: a nova configuração da gestão da educação na América Latina. Revista Brasileira de Política e Administração da Educação, Porto Alegre, v.24, n.3, p. 389-406, set./dez. 2008.

CASTRO, Maria Helena Guimarães. A Institucionalização da Política de Avaliação da Educação Básica no Brasil. In: COLOMBO, Sonia Simões; CARDIM, Paulo A. Gomes et al. (Org.). Nos bastidores da educação brasileira: a gestão vista por dentro. Porto Alegre: Artmed, 2010.

CONFERÊNCIA NACIONAL DA EDUCAÇÃO BÁSICA Documento final. Brasília: MEC, SEA, 2008.

CRISTOV, L. H. da S. Educação continuada: função essencial do CP. In: GUIMARÃES, Ana Archangelo (Org.). O coordenador pedagógico e a educação continuada. São Paulo: Loyola, 2007.

DAVIS ET AL (Org.). Formação continuada de professores: uma análise das modalidades e das práticas em estados e municípios brasileirosEstudos \& Pesquisas Educacionais, n. 2, nov. 2011.

DEMAILY, Lise Chantraine. Modelos de formação contínua e estratégias de mudança. In: NÓVOA, Antônio. Os professores e sua formação. Lisboa: Dom Quixote, 1992.

DESTRO, Martha Rosa Pisani. Educação continuada: visao historica e tentativa de conceitualizacao. Cadernos Cedes, n.36, p.21-28, 1995.

DI GIORGI, Cristiano Amaral G. et al. Necessidades formativas de professores de redes municipais: contribuições para a formação de professores crítico-reflexivo. São Paulo: Editora UNESP; São Paulo: Cultura Acadêmica, 2010.

DOMINGOS SOBRINHO, M. Classe média assalariada e representações sociais da educação: A educação como signo e objeto representacional. In: MOREIRA, Antonia Silva Paredes; JESUINO, Jorge Correia (Org.) Representações sociais: teoria e prática. 2. ed. rev . ampl. João Pessoa: Editora Universitária da UFPB, 2003.

DOURADO, Luiz F. A escolha de dirigentes escolares: políticas e gestão da educação no Brasil. In: FERREIRA, Naura Syria Carapeto (Org.). Gestão democrática da educação: atuais tendências, novos desafios. São Paulo: Cortez, 2000.

DOURADO, Luiz F. (Org.). Plano Nacional de Educação (2011-2020): avaliação e perspectivas. Goiânia/Belo Horizonte: UFG/Autêntica, 2011.

ENS, Romilda Teodora; GISI, Maria Lourdes. Políticas educacionais no Brasil e a formação de professores. In: ENS, Romilda Teodora; BEHRENS, Marilda Aparecida. Políticas de formação do professor: caminhos e percursos. Curitiba: Champagnat, 2011. 265 p. (Coleção formação do professor; 4). 
ESTRELA, Maria Teresa. A formação contínua entre a teoria e a prática. In: FERREIRA, Naura Syria Carapeto. Formação continuada e gestão da educação. 2. ed. São Paulo: Cortez, 2006

FALSARELLA, Ana Maria. Formação continuada e prática de sala de aula: os efeitos da formação continuada na atuação do professor. Campinas, SP: Autores Associados, 2004.

FELDMANN, Marina Graziela. Formação de Professores e cotidiano escolar. In: FELDMANN, Marina Graziela (Org.). Formação de professores e escola na contemporaneidade. São Paulo: Editora Senac São Paulo, 2009.

FIORINI FILHO, João Alberto. Gestão da escola pública: o diretor em sua ação cotidiana. São Paulo, 1996. Dissertação (Mestrado)- Faculdade de Educação, Pontifícia Universidade de São Paulo, São Paulo, 1996.

FRANCO, Maria Laura Barbosa Franco; NOVAES, Gláucia Torres. Franco. Os jovens do ensino médio e suas representações sociais. Cadernos de Pesquisa. São Paulo, n.112, mar. 2001.

FREITAS, Alexandre S. de. Os desafios da formação de professores no século XXI. In: FERREIRA, Andrea Terez Brito; ALBUQUERQUE, Eliana Borges Correa de; LEAL, Telma Ferraz. Formação continuada de professores: questão para reflexão. Belo Horizonte: Autêntica, 2007.

FREITAS, Luis Carlos (Org). Avaliação: construindo o campo e a crítica. Florianópolis: Insular, 2002.

FUSARI, José Cerchi. Formação contínua de educadores na escola e em outras situações. In: BRUNO, Eliane Bambini G.; ALMEIDA, Laurinda R.; CHRISTOV, Luiza $H$. da Silva. O coordenador pedagógico e a formação docente. 2. ed. São Paulo: Edições Loyola, 2001.

GARCÍA, Carlos Marcelo. Formação de professores para uma mudança educativa. Portugal: Porto Editora, 1999. (Coleção Ciências da Educação - Século XXI, v.2).

GATTI, Bernardete Angelina. Análise das políticas públicas para formação continuada no Brasil, na última década. Revista Brasileira de Educação, v.13, n.37, janabr.2008.

GATTI, Bernardete Angelina; BARRETO, Elba. Professores do Brasil: impasses e desafios. Brasília: Unesco, 2009.

GATTI, Bernardete Angelina; NUNES, Marina Muniz Rossa (Org.). Formação de professores para o ensino fundamental: estudo de currículos das licenciaturas em pedagogia, língua portuguesa, matemática e ciências biológicas. São Paulo: FCC, 2010 (Textos FCC, n.29).

GAUTHIER, Clermont. Problemas Relativos à Determinação de um repertório de Conhecimentos específicos do ensino. In: GAUTHIER, Clermont. Por uma teoria da pedagogia. Ijuí: Unijuí, 1998. 
GILLY, Michel. As representações sociais no campo da representação. In: Jodelet, Denise (Org.). As representações sociais. Rio de Janeiro: UERJ, 2001.

GIOVANNI, Luciana Maria. O ambiente escolar e ações de formação continuada. In: TIBALLI, Elianda Figueiredo A.; CHAVES, Sandramara Matias; MARIN, Alda Junqueira (Org.). Concepções e práticas em formação de professores: diferentes olhares. Rio de Janeiro: DP \& A, 2006.

GOMES, Alberto Albuquerque. Identidades profissionais e representações sociais: a construção das representações sociais sobre "ser professor". In: PARDAL, Luis Antonio et al. (Org.). Educação e trabalho: representações, competências e trajetórias. Aveiro: Editora Aveiro, 2007.

IMBERNÓN, Francisco. Formação permanente do professorado: novas tendências. São Paulo: Cortez, 2009.

IMBERNÓN, Francisco. Formação continuada de professores. Porto Alegre: Artemed, 2010.

IMBERNÓN, Francisco. Formação docente e profissional. São Paulo: Cortez, 2000.

JODELET, Denise. Loucura e representações sociais. Petrópolis: Vozes, 2005.

JODELET, Denise. Contribuições das representações sociais para a análise das relações entre educação e trabalho. In: PARDAL, Luis Antonio et al. Educação e trabalho: representações, competências e trajetórias. Aveiro: Editora Aveiro, 2007.

JOVCHELOVITCH, Sandra. Vivendo a vida com os outros: intersubjetividade, espaço público e representações sociais. In: GUARESCHI, Pedrinho Arcides; JOVCHELOVITCH, Sandra (Coord.). Textos em representações sociais. 7. ed. Petrópolis: Vozes, 1995.

KRAMER, S. As crianças de 0 a 6 anos nas políticas educacionais no Brasil: educação infantil e fundamental. Revista Educação \& Sociedade, Campinas, v.27, n.96, n. esp., out.2006.

KUHN, T. A estrutura das revoluções científicas. São Paulo: Perspectiva, 2003.

LUCK, Heloísa. Mapeamento de práticas de seleção e capacitação de diretores escolares. Estudos \& Pesquisas Educacionais, São Paulo, n. 2, nov. 2011.

MADEIRA, Margot Campos; MADEIRA, Vicente de Paulo Carvalho. Representações socias do diretor de escola. Revista de Ciências Humanas, Florianópolis, n. esp. , p.269-277, abr. 2002.

MADEIRA, Margot Campos. A (re) construção da teoria na prática do professor: os sentidos da aprendizagem. Revista Psicologia da Educação, São Paulo, v.14-15 $1^{\circ} \mathrm{e}$ $2^{\circ}$ semestre. p. 207-222, 2002.

MAIA, Graziela Zambão Abdian. As publicações da ANPAE e a trajetória do conhecimento em Administração da Educação no Brasil. Marília, 2004. 196 f. Tese (Doutorado) - Faculdade de Filosofia e Ciências, Universidade Estadual Paulista, São Paulo, 2004. 
MACHADO, Nilson José. Cidadania e educação. 2. ed. São Paulo: Escrituras,1997. MARCHESI, Álvaro; MARTÍN, Elena. Qualidade do ensino em tempos de mudança. Porto Alegre: Artmed, 2003.

MANTOAN, Maria Teresa Egler. Inclusão Escolar: O que é? Por quê? Como fazer? São Paulo: Moderna, 2003.

MARIN, Alda Junqueira. Educação continuada: introdução a uma análise de termos e concepções. Cadernos CEDES, n.36, p.13-20, 1995.

MAUÉS, Olgaíses Cabral. Reformas internacionais da educação e formação de professores. Cadernos de Pesquisa, n. 118, mar./ 2003.

MAUÉS, Olgaíses Cabral; OLIVEIRA, J. F. A formação docente no Brasil: cenários da mudança, políticas e processos em debate. In: VIEIRA, Lívia Fraga; OLIVEIRA, Dalila Andrade. Trabalho na educação básica: a condição docente em sete estados brasileiros. Belo Horizonte: Fino Traço, 2012.

MILITÃO, Andréia Nunes; PERBONI, Fabio; MILITÃO, Silvio Cesar Nunes. A formação de professores na agenda dos movimentos sociais: da I CONAE ao II PNE. In: LEITE, Yoshie Ussami Ferrari; MILITÃO, Silvio César Nunes; LIMA, Vanda Moreira Machado Lima. Políticas educacionais e qualidade da escola pública. Curitiba: CRV, 2013.

MINAYO, Maria Cecília de Souza. O desafio do conhecimento: pesquisa qualitativa em saúde. São Paulo: Hucitec/Abrasco, 1994.

MINHOTO, Maria Angélica. Política de Avaliação da Educação Brasileira: Limites e Perspectivas. In: SOUZA, Angela Ricardo de; GOUVEIA, Andréa Barbosa; TAVARES, Taís Moura (Org.). Políticas educacionais: conceitos e debates. Curitiba: Appris, 2013.

MORIN, Edgar. Os sete saberes necessários à educação do futuro. São Paulo: Cortez, 2000.

MORIN, Edgar. Educação e complexidade: os sete saberes e outros ensaios. São Paulo: Cortez, 2002.

MOROSINI, Marília. Internacionalização da educação superior e qualidade. In: AUDY, Jorge Luis Nicolas. Inovação e qualidade. Porto Alegre: EDIPUCRS, 2008.

MOSCOVICI, Serge. A representação social da psicanálise. Rio de janeiro: Zahar, 1978.

NÓVOA, António. Os professores e sua formação. Lisboa: Dom Quixote, 1992.

NÓVOA, António. Formação de Professores e trabalho pedagógico. Lisboa:

EDUCA, 2002.

NUNES, Cely. Os sentidos da formação continuada de professores: o mundo do trabalho e a formação de professores no Brasil. Tese (Doutorado), Faculdade de Educação, Universidade de Campinas, 2000. 
PARDAL, Luis Antonio et al. (Org.). Educação e trabalho: representações, competências e trajetórias. Aveiro: Editora Aveiro, 2007.

PARO, Vítor Henrique. Administração escolar: Introdução crítica. $6^{\text {a }}$ ed. São Paulo: Cortez, 1993.

PARO, Vítor Henrique. Por dentro da escola pública. São Paulo: Xamã, 1996.

PARO, Vítor Henrique. Qualidade do ensino: a contribuição dos pais. São Paulo: Xamã,2002.

PERRENOUD, Philippe. Práticas pedagógicas, profissão docente e formação:

perspectivas sociológicas. Lisboa: Dom Quixote, 1993.

PERRENOUD, P. Prática reflexiva no ofício de professor: profissionalização e razão pedagógica.Porto Alegre: Artmed, 2002.

SALES, Luis C. O valor simbólico do prédio escolar. Teresina: Edufpi, 2000.

SALES, Luis C. Qualidade na educação: entre a indefinição e a ação. In: NASCIMENTO, Ilma Vieira do; MELO, Maria Alice; DIAS, Ana Maria Iório (Org.). Política de pós-graduação: projetos de Pós-Graduação. São Luís: EDUFMA; Teresina: EDUFPI, 2009.

TARDIF, Maurice. Saberes docentes e formação profissional. Petrópolis: Vozes, 2002.

VASCONCELOS, Maria Lucia M. Carvalho. Gestão e qualidade do ensino. In: COLOMBO, Sonia Simões; CARDIM, Paulo A. Gomes. Nos bastidores da educação brasileira: a gestão vista por dentro. Porto Alegre: Artmed, 2010.

VIDAL, Eloísa Maia; VIEIRA, Sofia Lerche. Estudos \& Pesquisas: contribuições para políticas educacionais. Estudos \& Pesquisas Educacionais: relatório final. São Paulo: Fundação Victor Civita, 2013.

VIEIRA, Lívia Fraga; OLIVEIRA, Dalila Andrade. Trabalho na educação básica: a condição docente em sete estados brasileiros. Belo Horizonte: Fino Traço, 2012.

VIEIRA, Sofia Lerche. Políticas internacionais e educação: cooperação ou intervenção? In: DOURADO, Luiz Fernandes e PARO, Vitor Henrique. (Org.) Políticas públicas \& educação básica. São Paulo: Xamã, 2001.

ZAINKO, Maria Amélia Sabbag. Gestão do Conhecimento: o desafio da formação inicial e continuada de professores. In: ENS, Rominda Teodoro; VOSGERAU, Dilmeire Ramos; BEHRENS, Marilda Aparecida. Trabalho do professor e saberes docentes. Curitiba: Champagnat, 2012.

ZEICHNER, Kenneth. A formação reflexiva de professores: ideias e práticas. Lisboa, Portugal: EDUCA, 1993.

WERLE, Flávia Obino Corrêa. Sistema de avaliação da educação básica no Brasil: abordagem por níveis de segmentação. In: WERLE, Flávia Obino Corrêa. (Org.). Avaliação em larga escala: foco na escola. São Leopoldo: Oikos; Brasília: Liber Livro, 2010. 
Publicado em: Abr/2017 